\title{
Ulàpeitök: Using Bribri Indigenous Teachings to Develop a Ph.D. Research Methodology
}

\author{
Olivia Sylvester, Alí García Segura
}

\begin{abstract}
Although there is a growing interest in Indigenous research, education regarding how to put Indigenous research into practice is not often part of academic training. To increase the awareness of how Indigenous methodologies can be applied to academic research, we describe how we used Bribri Indigenous teachings to develop a Ph.D. research methodology for a food security project in Costa Rica. Our research approach was based on a Bribri concept related to cooperation, uläpeitök; this concept guided our work and helped to reduce the negative consequences associated with conventional research with Indigenous people (e.g., extractive practices, reinforcement of gender inequality, misrepresenting cultural information). We identified three considerations that may be useful for other scholars applying Indigenous teachings to academic research: 1) build flexibility into the entire research program, 2) ensure that community-level and university-level researchers are willing to play multiple roles beyond those associated with conventional research, and 3) proceed with an ethic of friendship. Our work is relevant to scholars working in Indigenous/non-Indigenous research teams that aim to transform conventional research approaches to ensure that they support human rights, equity, and cultural continuity. In Costa Rica, our research is specifically relevant to building wider acceptance of Indigenous methodologies in higher education.
\end{abstract}

KEYWords Costa Rica, ethics, Indigenous methodologies, qualitative research

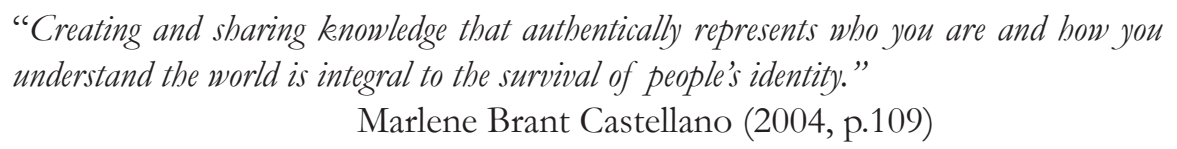

This opening quotation by Marlene Brant Castellano eloquently sums up what motivated our collaborative partnership to create, implement, and disseminate a research project based on Bribri Indigenous values and ethics. Developing this Bribri research project is important because, in Costa Rica, Indigenous peoples have been part of academic research designed and interpreted through outsider research frameworks since at least the late 1800s (e.g., Gabb 1875). Thus, despite the large body of literature on Indigenous peoples in Costa Rica, there has been little evidence that it has led to support of cultural continuity, language preservation, and/or other issues related to human rights (e.g., food security, self-determination; Alí García, personal communication). 
One telling example that illustrates how research that uses outsider frameworks may not support cultural continuity comes from the Térraba Indigenous Territory in Costa Rica. Anthropologists have been studying the Térraba language and culture since the 1960s, a book has been created about the Térraba language, but over this period of time, the language has become endangered (i.e., it has few speakers and is not commonly being learned by youth). This example illustrates that despite decades of research on the Teribe culture and language, this research has done very little for language continuity for the Teribe people.

That Western extractive research approaches have not succeeded in producing positive results for people's collective rights to self-determination and to cultural continuity is not unique to Indigenous people in Costa Rica. Indigenous scholars have widely described how research done within the dominant research paradigm has contributed to Indigenous peoples' colonization and oppression and to a worsening rather than an improvement of the conditions being studied (Tuhiwai Smith 2012[2009], Chilisa 2012, Wilson 2008, p.19). These scholars have collectively called for a new approach that does not insert Indigenous people into the dominant research paradigm, nor does it try to adapt Western research tools to include Indigenous perspectives. These scholars propose an approach that emerges from Indigenous peoples' distinct way of viewing the world and of living in it (Wilson 2008, p.15). Specifically, some unique characteristics of an Indigenous research paradigm include 1) knowledge emerging from relationships with the land as well as from non-human beings, and 2) researchers demonstrating relational accountability to people, clans, places, and non-human beings. In other words, there are different ways of knowing about a research topic that go beyond gathering verbal or written data from participants. Furthermore, there is a need to ensure that research acknowledges, respects, and addresses the needs of one's family, clan, and cultural spaces and places.

Our research emerges from this Indigenous conceptual framework, one that recognizes: 1) distinct ways of knowing and being, 2) the need to generate knowledge using tools that emerge from an Indigenous worldview to produce "a better understanding of, and provision for, the needs of Indigenous people" (Wilson 2008: 20), and 3) the need to evaluate Indigenous research based on Indigenous and not Western criteria.

Our research aims to make three important contributions to the Indigenous methodologies literature. First, there is a growing body of literature on Indigenous methodologies, most of which comes from the global north (Tuhiwai Smith (2012)[1999], Kovach 2009, Wilson 2008); thus, our work makes an important contribution to describing the process of developing and implementing Indigenous methodologies in the southern (Chilisa 2012) and Latin American context. Second, at a global scale, there is more research that describes Indigenous methodological principles and fewer studies that describe the process of applying them. Describing methodological implementation will provide examples for scholars who wish to use Indigenous methodologies but who are not aware of what that would look like in practice. Both authors of this paper work in academic institutions in Costa Rica and find that emerging scholars express this common concern; thus, our paper will provide guidance to these scholars. Describing how to practice Indigenous research is also important for academic institutions to

Engaged Scholar Journal: Community-Engaged Research, Teaching, and Learning 
gain familiarity with unconventional approaches; this familiarity will help institutions create more inclusive research guidelines (e.g., research ethics protocol). Third, our work contributes to a small body of literature on the implementation of Indigenous methodologies by a team of Indigenous and non-Indigenous scholars (and to the wider literature on insider-outsider research teams; Blodgett 2014, Kovach 2009).

\section{History of Research Regarding Bribri People}

The Bribri people are one of the eight Indigenous groups that live in Costa Rica. There are multiple Bribri territories in Costa Rica. Specifically, the Cabagra and Salitre Territories are located on the Pacific side of Costa Rica and the Talamanca and Këköldí Territories are located on the Atlantic side. The latest census reports 12,785 Bribri people in Costa Rica (INEC 2011). Around 70\% of Bribri people speak Bribri, a Chibchan language.

The historical context of academic research regarding Bribri people is important for understanding how our work makes a unique contribution to Bribri research. Some of the first anthropological research published about Bribri people appeared at the end of the 19th century (e.g. Gabb 1875). Historian Mauricio Menjivar Ochoa (2014) describes how this research, authorized by colonial endeavours (including those of the United Fruit Company), has heavily shaped how Bribri people have been portrayed in the literature. Overall, the content of this $19^{\text {th }}$-century documentation about Bribri people depicted them as inferior and uncivilized; these documents were used to justify their colonization and oppression, a commonality among Indigenous peoples internationally (Tuhiwai Smith 2012[1999]).

Since the early $19^{\text {th }}$ century, anthropologists have continued to work with Bribri people and have built upon the knowledge generated by these early naturalists and anthropologists (Bozzoli 1979). A large body of anthropological literature about Bribri people exists regarding their history, language, stories, social relations, traditions, religion, economy and their use of plants and natural resources (e.g., Whelan 2005, García-Serrano \& del Monte. 2004, Villalobos \& Borge 1998, Bozzoli 1979); the majority of this body of work has been carried out by non-Indigenous researchers using Western research methodologies. To our knowledge the only academic works published to date from a Bribri perspective, are those authored or coauthored by Alí García (hereafter Alî), author of this paper (e.g., García Segura 2016; Jara Murillo \& García Segura 2003; Jara Murillo \& García Segura 1997; García Segura 1994).

Although scholars have heavily analyzed Bribri people in academe, little attention has been given to the methods used to do so or to their impacts. In Costa Rica, it has been taken for granted that extractive outsider research, based on eurocentric values, is the way research in academia is done. Both authors of this paper work in national academic institutions in Costa Rica, and we have found it common that our non-Indigenous colleagues are not familiar with the concept of an Indigenous methodology.

That the academic community in Costa Rica has not fully recognized Indigenous methodologies relates to the same reasons that these approaches have not been fully recognized in academia elsewhere. Margaret Kovach (2009, p.156) describes these reasons: 1) an active resistance to change, 2) a passive non-awareness, and 3) a lack of understanding of what 
Indigenous methodologies would look like in practice. We have explained how we applied a Bribri research paradigm to a graduate academic project to address resistance, passive nonawareness, and lack of knowledge about Indigenous methodologies in academia in Costa Rica and elsewhere.

\section{Relevance of Indigenous Methodologies in Academia in Costa Rica}

Much of the information about Bribri people written by non-Bribri scholars has misrepresented Bribri knowledge and activities. When outsider research approaches are used (especially those that are done in short periods of time without in-depth knowledge of language and cultural context), Bribri people have tended to provide simple and superficial information to researchers; this phenomenon is further complicated by the fact that Bribri people may feel obligated to tell researchers what they want to hear because Bribri people do not feel comfortable sharing accurate information because of either past discrimination and outsiders' unfamiliarity with Bribri practices and life. Bribri methodologies need to be developed, described, and disseminated to ensure that researchers support a process in which people are comfortable sharing accurate information about themselves.

The purpose of our paper is to describe the process of applying Bribri teachings, values, and ethics to a doctoral research methodology. This paper is organized as follows. It begins with a background of our project. We follow with a description of how the Bribri concept of ulappitök guided our work and the creation of tools to gather information. We close by presenting a critical discussion of our work. Throughout this paper, we chose the word colleague to refer to the Bribri people who participated in this project; this is because we felt it best described the process of mutual knowledge sharing among authors and community members.

\section{Authors and Project Background}

Alí is a Bribri researcher of the Sébliwak clan and works in the linguistics department of the University of Costa Rica. He has been selected by community leaders and Elders to guide Bribri research and he has done so for over 20 years. Specifically, one highly respected community leader, the late $A w a$ (Bribri traditional doctor) Don Francisco García, requested that Alí engage in Bribri research using Bribri teachings and ethics and since then he has continued this work.

Olivia is a non-Indigenous Canadian of Irish descent with academic background in environmental management; she has spent the past decade studying and doing research in Costa Rica, and has lived there. Her Ph.D. dissertation topic was to examine Bribri people's wild food access in Costa Rican forested lands (Sylvester \& García 2016 and Sylvester et al. 2016 a,b,c). Alís interest in collaborating on this Ph.D. project was to document information about Bribri food harvesting using a Bribri methodology, to produce information that accurately represents Bribri people.

\section{Initial Project Development}

Our project took place in Alís home community, Bajo Coen (Figure 1). Before Olivia was 
invited to Alís community to start talking about what the project would look like at the community level, Olivia was taught for over two years about the social, political, and cultural context of Bribri people. This learning took place during weekly meetings with Alí. Olivia was exposed to teachings, stories, ethics, and history in a Bribri way. Olivia remembers techniques she was exposed to such as non-judgmental listening, non-hierarchical sharing, and respecting each other's learning paces; these are Indigenous values reported by other scholars (e.g., Wilson 2008).

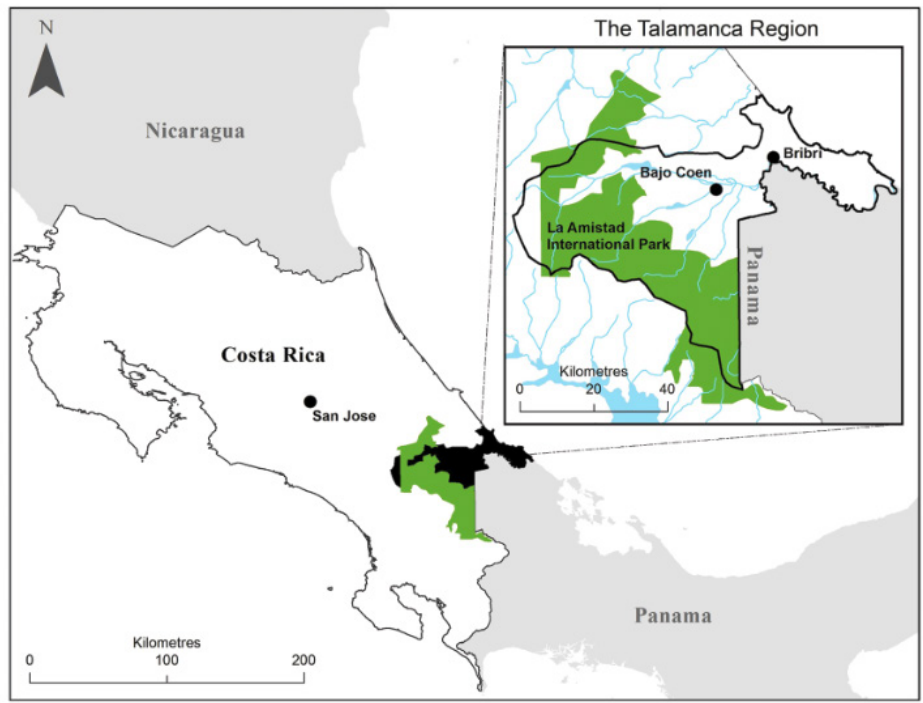

Figure 1: Map of the Talamanca region and the town of Bajo Coen where this research was carried out (map created by Justin Geisheimer).

Our intentionally slow pace promoted in-depth learning. If Olivia had rushed through the process merely reading about different Indigenous worldviews, methodologies, and not internalizing this information, she would not have achieved the level of understanding she now has about Bribri people and the importance of using Indigenous methodologies to contest a difficult history of discrimination and oppression. She describes this process in her research journal in 2012:

When I first sat down with Alí, I asked him if we could work together to better understand Indigenous peoples use of resources to help inform national parks of community conservation efforts. This [desire] was me wanting to take information from Bribri communities and insert it into existing conservation models, this was me generalizing about Indigenous practices, this was me breaking down relationships, taking Indigenous knowledge without its names, faces, and/or histories, without its places and wanting to bring it into conservation board rooms. Now, I sit down with Alí from a different starting point. I ask him how we can work together to support 
his family and clan members, such as his sister Ms. Sebastiana Segura or his mother Ms. Anastasia Segura, to create projects important for their social, educational, and cultural goals, such as...the traditional shifting corn farming project.

Although Olivia did choose to carve out a space in her program to take things slowly, there were times when she felt the need to speed up her research project based on her advisory committee's recommendations (e.g., to boost her publication record). There were also times she was hesitant to or did not have the confidence to explain that she needed more time in her methodology, because she was a graduate student in a highly competitive educational system that thrives on the products of research. However, she believes that being taught Bribri values early on helped to build her confidence to explain to her academic peers why this project needed to take a different pace than what is usually found in the dominant academic paradigm.

Alí made decisions about the pace of this project that allowed him to maintain accountability to his family. Alí explained that he did not want to define the methodology of this project until Olivia was sure that she could commit to the project as it would be defined by his Bribri colleagues. This was intentional on his part because he has worked with many researchers in the past who commit to different elements of a project but then come to "the field" and claim they do not have the time nor the funds to do the project in a way that is meaningful to Indigenous people; this is disappointing to Bribri community members, and it communicates that their needs and ideas are not being taken seriously.

\section{Building Relationships with Bribri Community Colleagues}

One protocol that academic researchers need to comply with is research ethics. At the time of our research, there were no written guidelines concerning the community-level organization that should be consulted prior to this research. Past non-Bribri people who have done research in the Bribri Talamanca territory told Olivia she would need to seek ethics approval from the Bribri Talamanca government (ADITIBRI), the state-approved governing body for this territory. Olivia discussed this with Alí, and he explained that this was not a traditional Bribri governing body; it would be more appropriate to receive approval through traditional processes of accountability. A Bribri person is first accountable to their family, then to their clan, and thirdly to their community. Consequently, Alí decided it was best to work through his family and clan relationships for this research, and he sought approval through these networks. Thus, although a state-appointed Bribri government does have a process to approve research, we made a conscious choice to use traditional Bribri institutions for our ethics approval process. Working with traditional Bribri networks of accountability greatly enriched our project; it shifted the power to Bribri authorities to determine the research approach and this ensured that our outcomes were meaningful to our community colleagues.

\section{Sëbliwak Women's Group}

Alí chose to work with the Sébliwak women's group (hereafter the Sébliwak group) in his home community for three main reasons: 1) his sister is the president of this group, 2) most 
members are from his clan (thus he is accountable to his family and clan), and 3) this group was interested in our food harvesting research topic. This group was composed of nine members and their families. Ali met with members of the women's group and there were three important outcomes of these meetings. First, all members of the Sébliwak group expressed interest in collaborating and working with us on how to best do so. Second, Olivia was invited to meet with the group. Third, members of the Sébliwak group self-selected their roles in the project and some of their desired outcomes.

Although Olivia felt it was important to attend these initial meetings, she later learned why her absence was important. She learned from the women within the Sébliwak group that researchers have imposed their research ideas and approaches on community members in the past. Even when women have requested changes to these methodologies, researchers have told them these changes are not possible for a number of reasons. Because of this history, our Bribri colleagues explained that they do not always feel completely comfortable asking outsiders to design research to account for the needs of the group and the community. Reflecting on this history, Olivia now feels it was important that she was not present at these initial meetings because of the power imbalance it could have created that could have limited people's ability to share their needs, and their desired outcomes for the project.

\section{What a Bribri Methodology Looks Like in Practice}

\section{Using Ulàpeitök to Guide our Research}

Alí and the women's group proposed to develop a research approach based on a Bribri concept called uläpeitök. Uläpeitök translates to lend (peitök) a hand (ulä) and is a Bribri concept related to helping each other with work. For instance, when a person is growing corn using shifting cultivation (where plots are cultivated then left for regeneration), people can ask their friends or relatives for uläpeitök, i.e., help farming. Uläpeitök is not limited to agriculture however; it can apply to other tasks (e.g., to cut a tree or to clean up an area of the community). When someone asks others for ulapeitök there is an understanding that the person requesting help will provide a meal and $b l o$ '(chicha, a fermented drink) to the people working. Furthermore, there is an understanding that if someone has asked you for ulapeitök, you can ask the same of that person in the future, for a project of your desired interest. Because uläpeitök is a traditional teaching on how to share work, our colleagues suggested we apply this to our project as a way to work together.

Uläpeitök informed how we defined the project outcomes. Specifically, we developed this research so it would result in benefits for all participants. Alí would benefit by applying a Bribri methodology to an academic project. Members of the Sébliwak group would receive funding and other forms of support with one of their food harvesting projects. Olivia would gain teachings and information necessary for her to complete her Ph.D. thesis.

By working with members of Alís family and clan, we were able to use Bribri criteria to determine the outcomes of our work; these community members added another dimension to the project that was not contemplated by the primary researchers alone. Specifically, members 
of the Sébliwak group wanted to ensure that this project would assist more than the nine families of the women's group; this was because, as Ms. Sebastiana Segura, the Sébliwak president, explained, for Bribri people one important value is not to be stingy. Thus, it was important for these women that the benefits reached as many community members as possible. For this reason, Sébliwak women requested that Olivia teach English classes to Bajo Coen residents. English classes were important for youth because at the time of our work the community primary school did not have an English teacher, but when these students move on to high school, they are required to have a Grade Six English level to enter into Grade Seven English (Figure 2).

Uläpeitök also informed how we shared research benefits (e.g., research funding). Members of the women's group assisted Olivia in acquiring Bribri teachings. Olivia assisted the women's group (with funding and labour) to support their corn farming project (Figure 3). Olivia and the Sébliwak group also worked together to successfully find funding for a second food harvesting project to grow organic coffee (Figure 4).

Overall, using uläpeitök as a guide to define our research partnership was central to shifting power to our community colleagues so they could define an approach compatible with their values and address on-the-ground needs of their community. Without the input of women early in the project, Olivia would have never imagined taking on the role of an English teacher, nor would she have understood the need to incorporate community accountability, i.e., extending benefits to as many community members as possible.

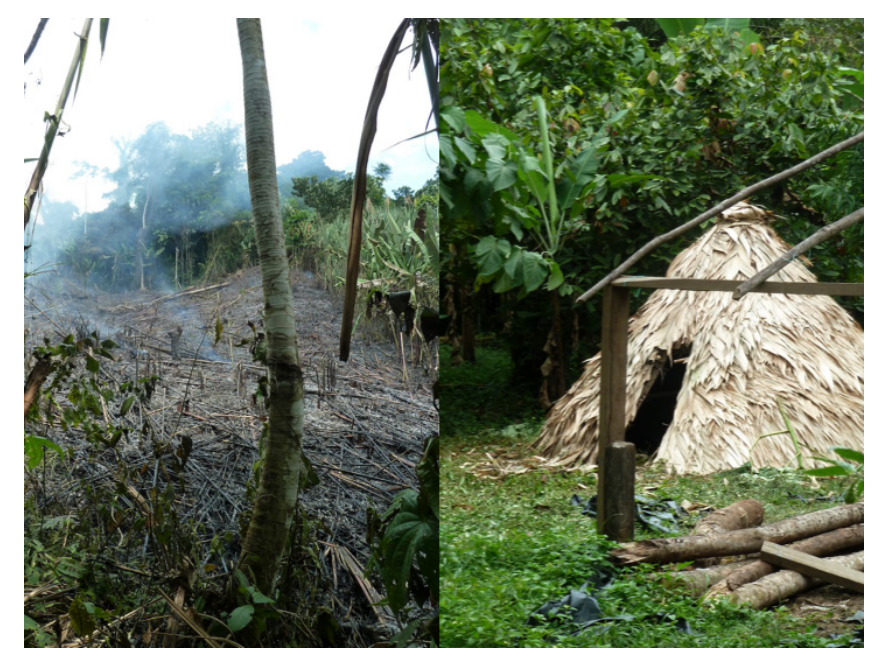

Figure 2: Shifting corn cultivation project (left) to grow corn to feed chicken being raised in the structure on the right called tòl. 


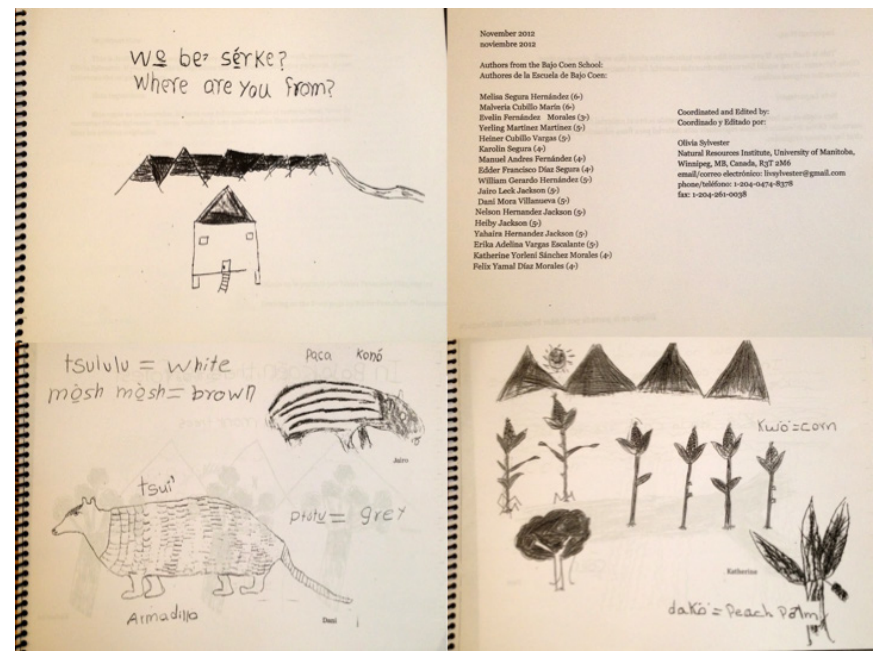

Figure 3: Sample pages of a book created by Bajo Coen community school students as part of English classes; students' names appear beside illustrations and the top left illustration was done by Edder Díaz Segura.

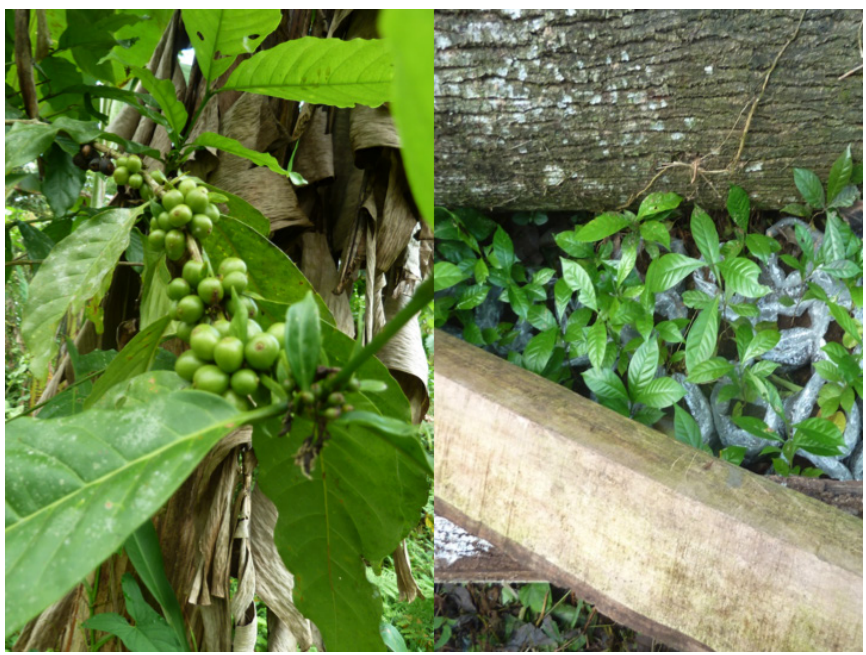

Figure 4: Organic coffee project. Seeds were purchased from Elders in Bajo Coen (left) and seedlings were grown by members of the Sébliwak group.

\section{Using Bribri teachings to guide learning and information gathering}

In this section, we describe how our information gathering methods were developed using Bribri teachings and practices. 


\section{Working with Family and Participating in Daily Life}

Indigenous scholars explain why it is important to work with family as intermediaries to invite people into your research; the researcher is then responsible to themselves as well as to a circle of relations, i.e., what Shawn Wilson (2008) calls relational accountability. Reviewers of this paper highlighted that working with family may be viewed as causing a conflict of interest for non-Indigenous audiences. For Alí, this conflict of interest is not perceived because for Bribri people, status is not related to resources or one's profession; although Bribri people may have different knowledge, experience, or professions, every Bribri person is valued as an equal. We now further elaborate on why working with family is important.

Working with family gives a research participant the chance to ask the family intermediary direct questions about the nature of the research and its motives and to decline participation to the intermediary (Wilson 2008; 129, paraphrasing Webber-Pillwax). This latter point is important for Bribri people, who explained to Olivia that it is not Bribri culture to deny someone knowledge or information. In this case, working with intermediaries can allow Bribri participants to gain necessary information about the research and to decline participation if needed without disrespecting cultural norms. Because Olivia did the majority of interviews with a community colleague Ms. Sebastiana Segura (hereafter Sebastiana), participants had the chance to ask questions with a trusted intermediary before accepting or declining participation. After these conversations with Sebastiana, three people that we approached to interview declined, a choice that, as Alí and Sebastiana explained, people would not likely have felt comfortable doing if an outsider had requested their participation.

Living life in a Bribri way was the best way to get a Bribri education, one that did not compartmentalize education about food harvesting from other Bribri values and practices. To better understand what we mean by this, we provide the example of banana farming. Banana farming is a key source of income for people in the Bajo Coen community. To understand banana farming through participation, you can choose two different ways. If you participate only in the cutting and planting aspect of farming, you will get an idea about how people farm or harvest, how much they harvest, and perhaps you can narrowly describe the gender dimensions of farming. If you participate in daily life, you will be up at 3 am helping the household women prepare the fire to make sure everyone has breakfast before farming, you will appreciate how families have to work together to get children on their way to school before farming and how women and men, young and Elder, work together to get baskets and machetes ready for work. If you participate in daily life, you will also experience how tired people can be after three or more hours in the hot sun, with their hands calloused from machete work; while you recuperate, you will hear stories and teachings as you rest in hammocks under shaded palm thatched roofs. If your participation is prolonged, you will travel every two weeks by foot to pick up your pay for harvesting bananas; you will see how challenging it is to earn a monthly salary when one kilogram of bananas is sold at around 10 cents (US currency).

Specifically, participation helped to build strong friendships; among many things, these friendships were important for women to feel comfortable participating in this research. Our 
female colleagues expressed their appreciation of Olivia's attempt to adapt in many ways to their day-to-day life; examples women mentioned was that Olivia worked with people in banana farming, went to Bribri doctors to be treated for illness, ate the same food as her colleagues, and maintained the same daily schedule as our colleagues (i.e., rising at 3-4am and sleeping at 6-7pm). Bribri colleagues contrasted these actions with those of other researchers; specifically, our female colleagues explained that past researchers have been reluctant to participate in Bribri work and elements of daily life. Although researchers would ask many questions about Bribri knowledge and practices, they would not engage in these practices themselves. For instance, Sebastiana explained that when she had participated in interviews in the past, after the interview, people would retreat to their rooms and some people would not even eat with her and her family. Sebastiana and our other female colleagues interpreted these practices to mean that people either had an aversion to Bribri food and/or were disinterested in Bribri life and culture. Members of the Sébliwak group said this lack of interest in Bribri women's lives, work, and culture caused them to feel reluctant to share Bribri teachings with researchers.

A second benefit of participation was that it helped Olivia understand women's unique barriers to engaging in academic research. Scholars have observed how women can experience a triple workload (e.g., work outside of the household, household maintenance, and childcare) which is a barrier to women's participation in research (Leach et al. 2016, Pfeiffer \& Butz, 2005). As a consequence, women's full contributions to food harvesting have not been adequately represented in the published literature (Pfeiffer \& Butz 2005, Howard, 2003, Brightman 1996). Understanding this suite of obstacles that female colleagues experienced was important to modify our research approach to minimize for women who wished to participate in research and to help Olivia limit the demands on women's time so as not to add to their workload. To meet these two goals, participation was critical. Olivia worked with women in banana fields, in community schools, and in households. Her work with women freed up time for them to help her with her research and/or it allowed Olivia and colleagues to converse while they were doing other daily activities.

A third benefit of our approach was that it helped our project progress at the pace of people's daily life. This was important to our female colleagues because, as they explained, if this pace is not a priority, projects can interfere negatively in women's lives. Female colleagues explained that many past researchers only started to wake up around eight or nine in the morning; in these cases Bribri women have to stay around the house to make sure researchers have breakfast and have what they need for the day. As Sebastiana explained, her attending to researchers' needs had affected her work in the past: although she would normally be out of the house by six in the morning working in agricultural fields, when researchers have stayed with her, she had been held back from work because she needed to work around their schedules, preparing breakfast for them later in the day (e.g., 8am). She was pleased with participation as a research method because it allowed her to teach Olivia while keeping on top of her work (interview 14/12/13). 


\section{Visiting Friends and Conversation Interviews}

In her book, Indigenous Methodologies, Margaret Kovach (2009, p. 129) talks about the importance of finding a way back "to core values of what is responsible, respectful, and kind, to that which is ours not someone else's." This point resonates with how we did interviews. Specifically, our approach was shaped from the teachings of Sebastiana, Olivia's main teacher. Early in her stay in Bajo Coen, Olivia discussed her interest in interviewing people. Sebastiana, who has had experience interviewing and being interviewed herself, explained that it was important for Olivia to get to know each person well before requesting interviews. This meant that Olivia would travel with Sebastiana to visit people. That Sebastiana accompanied Olivia during her first visits to community colleagues was important to allow these colleagues to ask Sebastiana about who Olivia was and to find out more about her research.

Sebastiana also sent Olivia on her own to meet community colleagues; she did so by asking Olivia to bring food that we cooked or harvested to these people. Olivia later learned that sharing food with people is also an important part of daily life and maintaining relationships. After living in Bajo Coen for a few months, Olivia learned how important visiting people is in Bribri daily life. During visits people check in with each other about their family's health, people share food, and they discuss important community issues, such as those related to the land and its health.

It was only after many visits and conversations that Olivia invited people to be interviewed. When Olivia asked if she could talk to people about an issue or topic, our colleagues would always respond by referring to an interview as a conversation. Margaret Kovach (2009, p. 124) describes this conversation method as a way to provide "...space, time, and an environment for participants to share their story in a manner that they can direct without the periodic disruptions involved in adhering to a structured approach, as in an interview format."

Conversation interviews served as spaces for a two-way information sharing. Many of Olivia's colleagues said that this two-way sharing was important to learn more about Olivia, her culture, her expertise, and her experiences working with other rural communities. For example, Sebastiana told Olivia how these conversations were important to her because she was able to learn about different cultures and about the realities of other farmers in Costa Rica and elsewhere. These learning opportunities were important because she had not yet had the opportunity to finish her schooling nor did she have many chances to travel outside of her community; what she learned with Olivia are things that would be important to share with her children and grandchildren.

\section{Feedback from Research Colleagues}

We received positive feedback from our Sébliwak group collaborators. Over a period of nine months, Olivia met with the Sébliwak group during their monthly group meetings to check in about our collaboration and visited this community yearly after the project was completed. On December 16, 2013, Sebastiana shared one of her reflections:

This is the first thesis project that took us seriously. In the past I have asked that thesis 
projects help us out in some way, but people always tell us that it is not possible... so I thought that it was true, that people were not able to help us with things that we need like helping our [women's] group or giving English classes to our children; they [English classes] are something that we do not have here but they are needed. This project has been a great blessing for us, a great help.

We also received positive feedback from other Bajo Coen residents who were not directly involved in the project. Specifically, people expressed positive feedback related to Olivia's engagement with the Bribri language and in Bribri daily life and English classes. People talked to both Olivia and Sebastiana about how important it was that Olivia engaged with Bribri language and people's work and that Olivia cooked, shared, and ate locally harvested and traditional food. One of our colleagues and participants in this project, Mr. Ancelmo Díaz, described his impression of the project design. On October $24^{\mathrm{h}}, 2012$, he explained how he felt it was important that youth observed Olivia's engagement in many of the activities that are central to Bribri culture. This was important because some youth place higher value on outsider customs than on Bribri customs. Having an outsider engage in and value Bribri harvesting, work, and food, can be important to help youth see the value of Bribri cultural practices. Olivia felt a level of discomfort accepting praise for something that should be second nature for researchers, i.e., valuing the customs of people we work with. However, we included Mr. Díaz's insight because it was something that many of our colleagues voiced. His comment illustrates one of the challenging realities of colonization and social inequality that many Bribri people live.

We also received constructive feedback. A few of our colleagues found teaching Olivia was at times challenging because of language barriers. Although Olivia spoke Bribri in conversations that did not require elaborate explanations, teachings related to our research were mainly in Spanish. There were times when Sebastiana would tell Olivia that it was very challenging to explain a concept to her in Spanish that had a unique meaning in Bribri; and, she also faced an additional challenge because Spanish was both Olivia's and her second language. Scholars have stressed that the use of Indigenous languages in Indigenous research is fundamental to understand concepts not easily translated (Wilson 2008). We addressed these challenges by having Olivia work closely with Sebastiana and with co-author Alí, both Bribri language speakers who have reviewed the knowledge Olivia has shared in her thesis and publications; however, we acknowledge that many oversights could have been made considering Olivia was the central researcher and had only a limited knowledge of the language.

\section{Considerations for Future Practice}

\section{Build Flexibility into the Entire Research Program}

We all go into a research project with our own ideas of how a project should be run. Doctoral students are often asked to provide details regarding research plans, research tools, timelines, and use of funding early in the research process, even before developing a relationship with 
community-level collaborators. For these reasons, it is easy to get attached to a given data collection tool, schedule, and/or ways to use funding. In our experience, we were required to be flexible on all of these elements. One key example of this flexibility relates to our allocation of funding.

In our project we had not allocated funding to support a local-level farming project. Because the support for this corn project was a priority for the Sébliwak group, we modified our budget so this project was funded. At first, Olivia was not fully comfortable with this level of flexibility; this discomfort was due to her attachment to using funds to purchase cameras for her research as well as to her lack of experience sharing power to this extent with her research colleagues. Olivia was fortunate to have a supportive funding agency and an academic committee who understood the importance of shifting funding allocation to meet community needs. This flexibility is important if we wish to reduce power inequalities among graduate students and their community colleagues.

\section{Be Prepared to Play Multiple Roles in a Project}

Linda Tuhiwai Smith (2012[1999]) explains how one person must often perform many roles in collaborative research; examples of these roles include activist, researcher, family member, community leader, which are additional to a person's day job. Playing multiple roles was critical for the completion of our project. Sebastiana, for instance, took on the role of Olivia's primary teacher; this required her to balance this role with her other roles such as Sébliwak president, healer, family member, and farmer. She worked hard to carve out time to work with Olivia to visit research participants, carry out interviews, make time for our research discussions, and help Olivia interpret information gathered. Sebastiana often told Olivia that she would love to have unlimited time to sit and teach her all about Bribri life and history; however, this was often challenging considering her other multiple tasks.

Olivia experienced some challenges balancing her role as a researcher with other roles in this project. Specifically, in any given day Olivia was a researcher, an English teacher, and a member of the Sébliwak group. Some of these tasks required a lot of energy she did not anticipate (e.g., waking at 4 am to help around the house before laborious banana farming) and left her with little energy in the evenings to take notes on the lessons and teachings she learned that day.

Early in the project, Olivia was concerned that these extra commitments would not leave her time to complete the academic objectives of her Ph.D. Upon reflection, Olivia now feels her concern about not having time to collect the academic data was rooted in her narrow understanding of data and the learning process. Since her moving out of Bajo Coen, Olivia has realized that the richest teachings and information came from what she learned while participating in daily life. She learned that important lessons and teachings were shared just as much in day-to-day tasks, such as accompanying people to the doctor or to the bank, as when harvesting food with people. Playing multiple roles exposed Olivia to many aspects of the dayto-day that helped rather than hindered her understanding of her colleagues' teachings; this allowed her to gather information that was representative of her Bribri colleagues' lives and 
concerns, information that is hard to collect in snapshot ethnographies.

\section{Adopt a Research Ethic of Friendship}

In 2003, Jennifer Tillmann-Healy proposed friendship as a research method as a way for researchers to pursue high ethical standards. She explained that friendship and fieldwork are similar in many ways. First, for instance, to do both friendship and fieldwork, colleagues need to gain acceptance and trust. Second, colleagues need to learn new codes for behaviour and experience challenges, conflicts, and loss. Third, people should not be rushed and should approach these processes with the ebb and flow of everyday life. Tillmann-Healy's (2003) concept of an ethic of friendship resonates with our approach. As Tillmann-Healy did, we invested in an ongoing process of acceptance and trust in a way that was compatible with Bribri teachings. Olivia learned new codes for behaviour, such as approaching a research partnership from a Bribri concept of sharing (uläpeitök). Lastly, we did not rush data collection; instead this process occurred at the pace of everyday life.

\section{Conclusions}

Our research makes important contributions to the Indigenous methodologies literature. First, although there is a growing body of literature on Indigenous methodologies, most of which comes from the global north (Tuhiwai Smith (2012)[1999], Kovach 2009, Wilson 2008), our work makes an important contribution to better understanding Indigenous methodologies in Latin America. Second, our work illustrates the success and challenges of doing this work on the ground. Third, our work contributes to better understand how to prioritize Indigenous values while working on Indigenous / non-Indigenous research teams (Blodgett 2014, Kovach 2009).

Our research approach was based on Bribri practices, values and ethics; that these Bribri principles were central to our work helped us address the power inequalities common in conventional research. That the women's group we worked with suggested the Bribri concept of uläpeitök, or working together, to guide our collaboration, placed the values of non-hierarchical learning and cooperation at the core of our work. Specifically the value of cooperation was central to addressing gender inequalities that have emerged with conventional research in the past. Women emphasized that all of the research they have participated in has created extra workloads for women (e.g., washing researchers' clothes, cooking special meals for them, missing out on wage labour to attend to researchers). Working together using Bribri values of cooperation allowed women to propose ways to help Olivia gather information that did not interfere with their daily responsibilities; this was not only important to support gender equity (e.g., Leach et al. 2016), but to create scenarios where women felt respected. The respect women felt led to greater comfort in sharing information with researchers that accurately represented themselves and their culture.

Negotiating and transforming conventional research frameworks requires time, institutional and economic support, and a desire to do things respectfully (Cuerrier, Downing, Patterson, \& Haddad, 2012; Czaykowska-Higgins, 2009; Kovach, 2009; Tuhiwai Smith, 2012[1999]). We were 
fortunate to have institutional and economic support and Bribri collaborators who helped us understand how to proceed in a good way. Although our approach was not without challenges, overall, we achieved our goal, i.e., to apply Bribri teachings to a Ph.D. methodology with the goal of challenging, if only slightly, the conventional way of doing research with Indigenous people in Costa Rica. When this project began, Alí told Olivia it has taken over 500 years to attempt to colonize Bribri people, and reversing this process may take a similar period of time. In this context, Alí asserted that every attempt to decolonize research with Indigenous people, no matter how small, is important because it is contributing to an ongoing, lengthy process of decolonization. Our hope is that this project has made one small contribution to this process.

\section{Acknowledgements}

Wéste wéste, thank you to our Bribri colleagues who shared their teachings and provided guidance on presenting our research. A. Miller provided helpful suggestions on an earlier version of this manuscript. This work was carried out with the aid of a grant from the International Development Research Centre, Ottawa, Canada. Information on the Centre is available on the web at www.idrc.ca. This work was also supported by a Social Sciences and Humanities Research Council (SSHRC) Doctoral Fellowship awarded to Olivia, a SSHRC Grant awarded to Iain Davidson-Hunt, and the Aboriginal Issues Press at the University of Manitoba. The Sébliwak women's group, Elders in the Bajo Coen community, and the University of Manitoba Joint-Faculty Research Ethics Board approved this study.

\section{About the Authors}

Olivia Sylvester, Ph.D. (corresponding author) is an Assistant Professor of Sustainable Food Systems in the Environment and Development department at the United Nations-mandated University for Peace, Costa Rica. She uses Indigenous and feminist research approaches to better understand people's food access, gender, and human rights.

Email: livsylvester@gmail.com

Alí García Segura is a Bribri community member (Sébliwak clan) and professor in the Linguistics Department at the University of Costa Rica. He is an advisor to the Costa Rican government on Indigenous rights and education. He has written 10 books on Bribri language and culture.

Engaged Scholar Journal: Community-Engaged Research, Teaching, and Learning 


\section{References}

Blodgett, A. T., Schinke, R. J., McGannon, K. R., Coholic, D. A., Enosse, L., Peltier, D., Pheasant, C. (2014). Navigating the insider-outsider hyphen: a qualitative exploration of the acculturation challenges of Aboriginal athletes pursuing sport in Euro-Canadian contexts. Psychology of Sport and Exercise, 15, 345-355.

Brant Castellano, M. (2004). Ethics of Aboriginal research. Journal of Aboriginal Health, 1(1), 98-114.

Brightman, R. (1996). The sexual division of foraging labor: Biology, taboo, and gender politics. Comparative Studies in Society and History, 38, 687-729.

Bozzoli, M. E. (1979). El Nacimiento y La Muerte Entre Los Bribris. San Jose, Costa Rica: Editorial de la Universidad de Costa Rica.

Chilisa, B. (2012). Indigenous Research Methodologies. SAGE Publications, Inc.

Cuerrier, A., Downing, A., Patterson, E. and Haddad, P. (2012). Aboriginal anti-diabetic plant project with the James Bay Cree of Quebec: An insightful collaboration. Journal of Enterprising Communities: People and Places in the Global Economy, 6(3), 251-270.

Czaykowska-Higgins, E. (2009). Research models, community engagement, and linguistic fieldwork: reflections on working within Canadian Indigenous communities. Language Documentation \& Conservation, 3(1), 15-50.

Gabb, W. M. (1875). On the Indian tribes and languages of Costa Rica. Proceedings of the American Philosophical Society, 14(95), 483-602.

García Segura, A. (2016). Ditsò Rukuò. Gland, Switzerland: IUCN.

García Segura, A. (1994). Plantas de la Medicina Bribri. San Jose, Costa Rica: Editorial de la Universidad de Costa Rica.

García Segura, A. and Jara Murillo, C. V. (2003). Diccionario de Mitología Bribri. San Jose, Costa Rica: Editorial de la Universidad de Costa Rica.

García Segura, A. and Jara Murillo, C. V. (1997). Kó Késka. El Lugar del Tiempo. Historias y Otras Tradiciones Orales del Pueblo Bribri. San Jose, Costa Rica: Editorial de la Universidad de Costa Rica.

Garcia-Serrano, C. R., and del Monte, J. P. (2004). The use of tropical forest (agroecosystems and wild plant harvesting) as a source of food in the Bribri and Cabécar cultures of the Caribbean Coast of Costa Rica. Economic Botany, 58, 58-71.

Howard P. L. (2003). Women and the plant world. In Howard, P.L. (Ed.) Women and Plants: Gender Relations in Biodiversity Management and Conservation. London, UK: Zed Books Ltd.

INEC. 2013. Censo nacional de población y VI de vivienda: territorios Indígenas, Instituto Nacional de Estadística y Censos, Costa Rica.

Kovach, M. (2009). Indigenous methodologies: Characteristics, conversations and contexts. Toronto, Canada: University of Toronto Press.

Leach, M., L. Mehta, and Prabhakaran, P. (2016) Sustainable development: a gendered pathways approach. In Leach, M. (Ed.) Gender Equality and Sustainable Development. New York, USA: Routledge.

Menjivar Ochoa, M. (2014). Los indígenas bribris en la mirada antropológica de científicosnaturalistas: Costa Rica a fines del siglo XIX. Cuadernos de Antropología Social, 40, 97-124.

Pfeiffer, J. M., \& Butz. R. J. (2005). Assessing cultural and ecological variation in ethnobiological research: the importance of gender. Journal of Ethnobiology, 25(2), 240-278. 
Sylvester, O., \& García Segura, A. (2016). Landscape ethnoecology of forest food harvesting in the Talamanca Bribri Indigenous Territory, Costa Rica. Journal of Ethnobiology, 36(1), 215-233.

Sylvester, O., García Segura, A. G., and I. Davidson-Hunt. (2016a). Complex Relationships among gender and forest food harvesting: Insights from the Bribri Indigenous Territory, Costa Rica. International Forestry Review, 18(2), 247-260.

Sylvester, O., García Segura, A. G., and I. Davidson-Hunt. (2016b). Wild food harvesting and access by household and generation in the Bribri Indigenous Territory, Costa Rica. Human Ecology, 44(4), 449-461.

Sylvester, O., García Segura, A. G., and I. Davidson-Hunt (2016c). The protection of rainforest biodiversity can conflict with food access for Indigenous people. Conservation and Society, 14(3), 279-290.

Tillmann-Healy, L. (2003). Friendship as method. Qualitative Inquiry, 9(5), 729-749.

Tuhiwai Smith, L. (2012)[1999]. Decoloni₹ing methodologies: Research and Indigenous peoples, $2^{\text {nd }}$ edition. London, UK: Zed Books Ltd.

Villalobos, V. and C. Borge. (1998). Talamanca en la encrucijada. San Jose, Costa Rica: Editorial Universidad Estatal A La Distancia.

Whelan M.P. 2005. Reading the Talamanca landscape: land use and livelihoods in the Bribri and Cabécar indigenous territories. M.Sc. thesis, CATIE, Turrialba, Costa Rica.

Wilson, S. (2008). Research is ceremony: Indigenous research methods. Nova Scotia, Canada: Fernwood Publishing Co., Ltd. 